\title{
Ligation of the Intersphincteric Fistula Traject with Placement of a Prosthesis: A New Technique in the Treatment of Fistula-in-Ano at Yaounde Central Hospital (Cameroon)
}

\author{
Eric Patrick Savom 1,2, Georges Roger Bwelle Motto2,3, Guy Aristide Bang2,4, \\ Joseph Cyrille Chopkeng ${ }^{3}$, Ricardo Fomene Ngouanet ${ }^{5}$, Ghislain Loïc Batimba Nolabia ${ }^{2}$, \\ Arthur Essomba ${ }^{2,4}$ \\ ${ }^{1}$ Yaounde General Hospital, Yaounde, Cameroon \\ ${ }^{2}$ Faculty of Medicine and Biomedical Sciences of the University of Yaounde I, Yaounde, Cameroon \\ ${ }^{3}$ Yaounde Central Hospital, Yaounde, Cameroon \\ ${ }^{4}$ Yaounde Hospital and Teaching Centre, Yaounde, Cameroon \\ ${ }^{5}$ Higher Institute of Medical Technologies of Yaounde, Yaounde, Cameroon \\ Email: *chopkeng.c@gmail.com
}

How to cite this paper: Savom, E.P., Bwelle Motto, G.R., Aristide Bang, G., Chopkeng, J.C., Fomene Ngouanet, R., Batimba Nolabia, G.L. and Essomba, A. (2022) Ligation of the Intersphincteric Fistula Traject with Placement of a Prosthesis: A New Technique in the Treatment of Fistula-in-Ano at Yaounde Central Hospital (Cameroon). Surgical Science, 13, 66-77.

https://doi.org/10.4236/ss.2022.132010

Received: January 22, 2022

Accepted: February 21, 2022

Published: February 24, 2022

Copyright $\odot 2022$ by author(s) and Scientific Research Publishing Inc. This work is licensed under the Creative Commons Attribution International License (CC BY 4.0).

http://creativecommons.org/licenses/by/4.0/

(c) (i) Open Access

\begin{abstract}
Background: Ligation of the inter-sphincter fistula tract associated with anal plug (LIFT-Plug) is a new anal fistula treatment procedure at the Yaoundé Central Hospital. A two-sided prosthesis piece bent in the shape of a cone is used here as an anal plug. The aim of this work was to evaluate the therapeutic results and the safety of this device. Patients and Methods: The clinical data of patients operated by the LIFT-Plug technique from January 1, 2020 to June 30, 2021 for a high anal fistula were analyzed prospectively. The variables evaluated were operative time, cure rate, postoperative complications and recurrence rate. Results: We included 28 patients with a mean age of 42 years. The sex ratio was 1.15 . No patient presented preoperative continence disorder. The fistula was high trans-sphincteric in $89.3 \%$ of cases. The average duration of surgery was 55.2 minutes ( 45 to 66 minutes). The postoperative course was straightforward, although $60.7 \%$ of the patients had experienced tingling that resolved spontaneously. Three patients (10.7\%) presented with transient gas incontinence (WIS of 4) which completely resolved after one month. All patients healed within a mean of 63.21 days (25 to 95 days). At the end of the 6-month follow-up, no case of recurrence had been recorded. Conclusion: The LIFT-Plug is a simple, safe and effective technique for the treatment of upper anal fistula without major impairment of continence despite delayed healing. The adapted two-sided prosthesis is a good alternative to the conventional anal plug.
\end{abstract}




\section{Keywords}

High Anal Fistula, LIFT-Plug, Healing, Postoperative Complications, Recurrence

\section{Introduction}

Anal fistula is characterized by an abnormal communication between the anal canal and the surrounding perineal skin with a permanent purulent or faecal discharge and pain that impairs the patient's quality of life. Its treatment, which aims to dry up the suppuration while preserving continence, has always been a challenge for practitioners. This condition thus remains difficult for both the patient and the practitioner.

The treatment of anal fistula is almost exclusively surgical and involves many techniques. Fistulotomy and fistulectomy are historical techniques that have shown high cure rates. However, they require varying degrees of sphincter transection, putting the patient at high risk of incontinence [1] [2] [3] [4] [5] and preservation of continence often requires multiple operations or the use of sphincter-sparing techniques [6]. These include fibrin sealant injection, anal plug and ligation of intersphincteric fistula tract (LIFT).

Johnson et al. were the first to describe the anal plug, a bio-resorbable xenograft made from freeze-dried porcine intestinal submucosa [7]. They achieved an initial success rate of $86.7 \%$ at three months. LIFT was first reported by Rojanasakul et al. in 2007, with a promising initial cure rate of $94.4 \%$ [8]. These results have not always been confirmed in many subsequent publications that showed variable cure rates and often high recurrence rates [7] [9]-[22]. In an attempt to improve these figures, the two techniques were combined, resulting in an initial cure rate of $95 \%$ [23]. Following the description of the technique by Han et al., several studies have been published on inter-sphincter ligation with anal plug (LIFTPlug), with success rates ranging from $68.8 \%$ to $96.5 \%$ without major continence problems [17] [18] [24] [25] [26].

The treatment of anal fistula at Yaoundé Central Hospital $(\mathrm{YCH})$ has involved many techniques, including constrictor fistulotomy, with a cure rate of $85 \%$ without major alteration of continence [27]. The LIFT-Plug has recently been introduced into the therapeutic arsenal of anal fistulas in this facility. Here, the anal plug uses a non-absorbable material not designed for this indication. We therefore proposed to evaluate the therapeutic results and medium-term safety of this plug associated with LIFT in a group of patients with a high anal fistula.

\section{Patients and Methods}

\subsection{Patient Selection}

From January 1, 2020 to June 30, 2021 (18 months), patients over 18 years of age with a high anal fistula with or without diverticular tracts or a horseshoe fistula, 
and having history of prior drainage and tapping of their fistula, were operated on by the LIFT-Plug technique in the Visceral Surgery Department of the YCH (Cameroon).

The $\mathrm{YCH}$ is a second category hospital in the health pyramid of the country. It is a university hospital with almost all specialised services and receives patients from all social strata living in Yaoundé, its surroundings, and from more distant localities.

Patients with fistula associated with inflammatory bowel disease, radiotherapy, malignancy, pre-existing incontinence or chronic diarrhea were excluded from the study; as well as those with other proctological pathology (anal fissure and haemorrhoids) or with a defect that could impede the healing process (diabetes, cancers, chemotherapy, and corticosteroid therapy) were excluded.

The diagnosis of anal fistula was made clinically in all patients. Patients' continence was assessed using the Jorge and Wexner incontinence score (SIW) [28]. This study was approved by the ethics committee of the Faculty of Medicine and Biomedical Sciences of the University of Yaoundé I. Written informed consent was obtained from all patients after a full explanation of the procedure. They agreed to participate in regular follow-up assessments.

Information regarding patient demographics, history, fistula characteristics, operative data and follow-up results was collected using a data sheet. Each patient had a minimum of six months of follow-up and the last patient was to be recruited by $30^{\text {th }}$ November 2020 . Treatment failure was defined as persistence of discharge beyond four weeks after the surgery and recurrence was defined as recurrence of discharge or air leakage through the external opening and/or inter-sphincter incision after healing (healing of the external opening and intersphincter wound).

\subsection{Surgical Technique}

All patients were admitted the day before surgery without prior colonic preparation. Preoperative fasting was observed and a dose of Ceftriaxone $2 \mathrm{~g}$ antibiotic was administered intravenous at the time of anaesthetic induction. After general or locoregional anesthesia was administered according to the findings of the pre-anesthetic consultation, patients were placed in the gynecological position. The internal ostia was identified by injecting methylene blue or povidone-iodine from an external opening and the fistulous path was marked with a metal stylet from the external ostia to the internal ostia. A curvilinear incision parallel to the anal margin of approximately 1.5 to $2 \mathrm{~cm}$ was made in the inter-sphincter groove overlooking the fistula path previously marked by the stylet. A blunt dissection was performed in the inter-sphincter space to expose the fistula path (Figure 1). The dissected path was encircled and the stylet removed. It was then ligated near the internal sphincter with absorbable suture Vicryl ${ }^{*} 3 / 0$ (polyglactine) before being sectioned. The inter-sphincter tract was opened, curetted and washed with $0.9 \%$ saline. A piece of Ventralight $\mathrm{st}^{\circledR}$ (a two-sided prosthesis made of a medium 


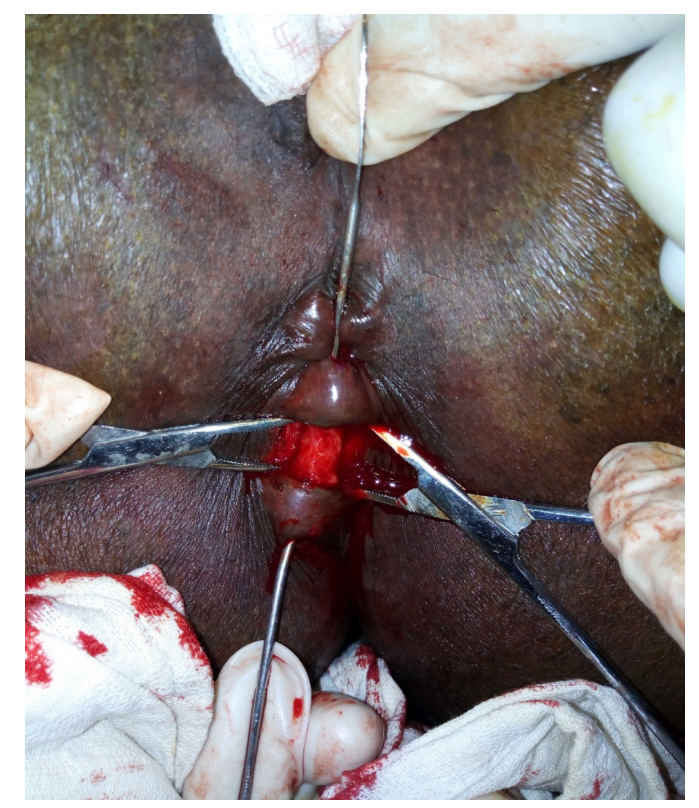

Figure 1. Dissection of the inter-sphincter pathway.

weight uncoated polypropylene monofilament on one side and an absorbable hydrogel barrier on the other side), $3 \times 5 \mathrm{~cm}$ in size, was soaked in saline and then rolled up into a cone shape to serve as an anal plug (Figure 2). It was inserted into the fistula path from the external orifice and secured with $3 / 0$ polyglactin at the external sphincter. The excess of the prosthesis was resected and the inter-sphincter wound was sutured. The external orifice was left open to facilitate drainage (Figure 3).

\subsection{Postoperative Follow-up}

All patients received antibiotics (Ceftriaxone and metronidazole) and analgesics (paracetamol, tramadol and diclofenac) intravenously for 24 hours. They were all discharged the next day with analgesia and faecal stool softeners. Sitz baths were routinely prescribed.

Patients were regularly reviewed weekly after surgery until healing, then monthly until the sixth month of surgery. At each visit, the patient's clinical continence status was assessed using the SIW. An examination of the surgical wound, internal and external orifices were performed and other complications were investigated.

\subsection{Statistical Analysis}

The data were analysed using SPSS 19 software. Qualitative data are expressed as frequency and quantitative data as mean and standard deviation.

\section{Results}

During the study period, 28 patients met our criteria and were included in the study. There were 15 men (53.6\%) and 13 women (46.4\%), giving a sex ratio of 


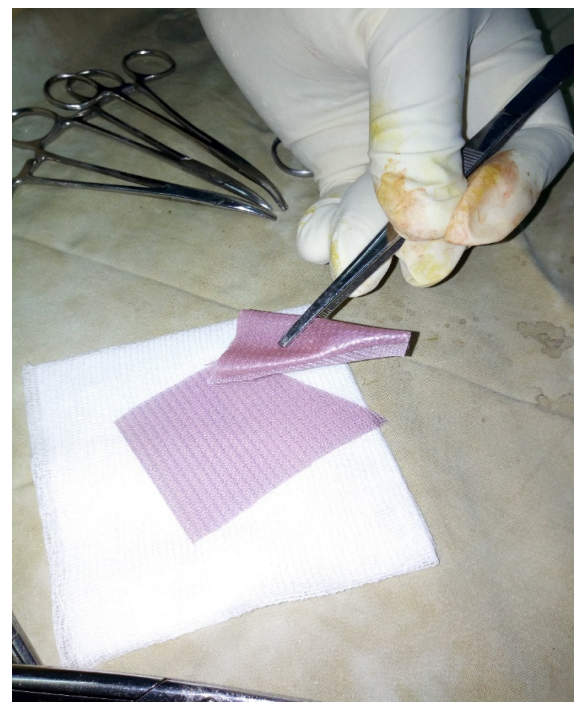

Figure 2. Preparation of the cone-shaped anal plug.

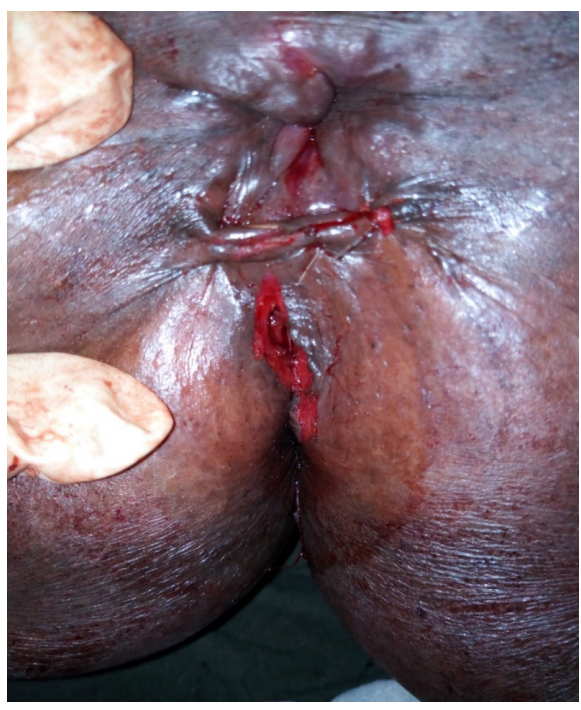

Figure 3. Postoperative appearance (inter-sphincter wound closed and external orifice left open).

1.15. Their mean age was 42 years \pm 24 - 68 years. The $35-45$ age group was the most represented (11 cases, 39.3\%). The majority of patients were hypertensive (17 cases, 60.7\%), one patient (3.6\%) had a recurrent anal fistula and one patient (3.6\%) had a history of anal trauma. The average body mass index (BMI) of our patients was $26.19 \mathrm{~kg} / \mathrm{m}^{2}\left(17.5\right.$ to $\left.32.2 \mathrm{~kg} / \mathrm{m}^{2}\right)$. Twenty patients $(71.4 \%)$ had a $\mathrm{BMI} \geq 25 \mathrm{Kg} / \mathrm{m}^{2}$ and 5 (17.9\%) were obese. All patients (28 cases, 100\%) had consulted for chronic perianal discharge, most often purulent (16 cases, $57.1 \%$ ), evolving for a mean of 7.93 months with extremes of 3.5 and 19 months. None of the patients had a continence disorder preoperatively. Inspection of the anal margin revealed a single external orifice in 26 cases (92.9\%). It was double in the other 2 cases $(7.1 \%)$. All patients had prior drainage of the discharge with a mean time to dryness of 4.46 months (2.75 to 7.5 months). In the majority of 
cases (64.3\%), the discharge had dried up between 3 and 6 months. No additional morphological examination was performed. Nineteen patients $(67.9 \%)$ were classified as ASA 1. The clinical epidemiology of the study population is summarised in Table 1.

All patients were installed in the waist position, under locoregional anaesthesia in the majority of cases $(21,75 \%)$. The internal orifice was identified in all cases and was most often posterior (15 cases, 53.6\%). The fistula tract was high trans-sphincter in 25 cases (89.3\%). We recorded 2 cases (7.1\%) of Y-shaped fistula and one case (3.6\%) of horseshoe-shaped fistula. The average duration of the surgery was 55.2 minutes with extremes ranging from 45 to 66 minute. No intraoperative complications were noted. Twenty-seven patients (96.4\%) were

Table 1. Clinical epidemiology of the study population.

\begin{tabular}{cccc}
\hline & Variables & N & Percent \\
\hline Sex & & \\
& Male & 15 & 53.6 \\
& Female & 13 & 46.4 \\
\hline Age & & \\
& $<25$ & 1 & 3.6 \\
& {$[25-35[$} & 5 & 17.9 \\
& {$[35-45[$} & 11 & 39.3 \\
& $745-55[$ & 7 & 25 \\
& 2 & 7.1 \\
\hline $55-65[$ & 2 & 7.1 \\
\hline History/Comorbidities & & \\
HBP & 17 & 60.7 \\
Alcohol & 22 & 78.6 \\
Tobacco & 13 & 46.4 \\
BMI & & \\
$<18.5$ & 1 & 3.6 \\
{$[18.5-25[$} & 7 & 25 \\
{$[25-30[$} & 15 & 53.6 \\
$>30$ & 5 & 17.9 \\
Fistulectomy & 1 & 3.6 \\
Anal trauma & 1 & 3.6 \\
HIV infection & 1 & 3.6 \\
\hline
\end{tabular}

\section{Preoperative SIW}

0 28 100

\section{External Orifice} Unique 26

Double

2

7.1

\section{ASA Classification}

$\begin{array}{ccc}1 & 19 & 67.9 \\ 2 & 9 & 32.1\end{array}$

HBP: High Blood Pressure; BMI: Body Mass Index; HIV: Human Immunodeficiency Virus; SIW: Jorge and Wexner Incontinence Score; ASA: American Society of Anaesthesiologists. 
discharged within 24 hours of the procedure and one patient (3.6\%) stayed two days after surgery due to severe postoperative pain and acute urine retention requiring trans-urethral catheterisation. The postoperative course was generally simple. However, seventeen patients $(60.7 \%)$ had experienced tingling that did not require any specific medication. Three patients (10.7\%) had experienced transitory gas incontinence (SIW of 4 ) which had completely regressed after one month. The average healing time was 63.21 days (25 - 95 days). The majority of patients $(60.7 \%)$ had healed by the third month. All patients had a 6-month follow-up and at the end of this follow-up, none of them had continence problems and no recurrence had been recorded. The operative and evolutionary data of the patients are reported in Table 2.

Table 2. Operative and evolutionary data of patients.

\begin{tabular}{|c|c|c|}
\hline Variables & $\mathbf{N}$ & Percent \\
\hline \multicolumn{3}{|l|}{ Type of anaesthesia } \\
\hline General & 7 & 25 \\
\hline Local & 21 & 75 \\
\hline \multicolumn{3}{|c|}{ Topography of the internal orifice } \\
\hline Anterior & 2 & 7.1 \\
\hline Posterior & 15 & 53.6 \\
\hline Right lateral & 4 & 14.3 \\
\hline Left lateral & 7 & 25 \\
\hline \multicolumn{3}{|l|}{ Type of fistula } \\
\hline High trans-sphincter & 25 & 89.3 \\
\hline Y-shaped & 2 & 7.1 \\
\hline Horseshoe & 1 & 3.6 \\
\hline \multicolumn{3}{|l|}{ Post-operative hospital stay } \\
\hline 24 hours & 27 & 96.4 \\
\hline$>24$ hours & 1 & 3.6 \\
\hline \multicolumn{3}{|l|}{ Postoperative SIW } \\
\hline \multicolumn{3}{|l|}{ At 1 week } \\
\hline 0 & 25 & 89.3 \\
\hline 4 & 3 & 10.7 \\
\hline \multicolumn{3}{|l|}{ At 1 month } \\
\hline 0 & 28 & 100 \\
\hline \multicolumn{3}{|l|}{ At 6 months } \\
\hline 0 & 28 & 100 \\
\hline \multicolumn{3}{|l|}{ Healing Time in day } \\
\hline $0-30$ & 1 & 3.6 \\
\hline $31-60$ & 6 & 21.4 \\
\hline $61-90$ & 17 & 60.7 \\
\hline$>90$ & 4 & 14.3 \\
\hline \multicolumn{3}{|l|}{ Recurrences } \\
\hline Yes & 0 & 0 \\
\hline No & 28 & 100 \\
\hline
\end{tabular}

SIW: Jorge and Wexner incontinence score. 


\section{Discussion}

LIFT-Plug is a surgical technique in the treatment of fistula introduced by Han et al. in 2011 [23]. In the original description, the authors used an acellular dermal matrix $(\mathrm{ADM})$ which a soft connective tissue graft generated by a decellularisation process preserving the intact extracellular skin matrix. During implantation, this structure serves as a scaffold facilitating subsequent cell repopulation and revascularisation by providing resistance to infection or contamination [29] [30]. Subsequently, other authors have used the Cook Surgisis AFP ${ }^{\mathrm{TM}}$ device which is a collagen-rich extracellular matrix made from freeze-dried porcine small intestinal submucosa. It contains growth factors and cytokines. It is designed in the shape of a cone to be placed in the fistula tract. These materials are not marketed in our country. Our team has adapted an anal plug by folding it into a cone shape, a two-sided piece of prosthesis made of a non-resorbable polypropylene monofilament on one side and an absorbable hydrogel barrier on the other side. It is therefore a non-absorbable material introduced into an infected and inflammatory environment. The aim of our work was to evaluate the therapeutic results and medium-term safety of this device.

Anal fistula is an abnormal communication between the anal canal and the surrounding perineal skin, most often originating from an infected anal gland. It is a chronic infection and inflammation with no tendency for spontaneous healing. Treatment is based on surgery, the aim of which is to remove the infection while preserving the patient's continence. It should therefore spare as much as possible the sphincter, crossed at variable height by the fistulous path. Traditional treatment by fistulotomy or fistulectomy, which is effective and safe in low fistulas, is not recommended in the case of high fistulas, due to a high rate of continence disorders [1] [2] [3] [4] [5]. Several treatment alternatives have been developed. Fibrin sealant injection, anal plug and LIFT are procedures that have been widely used in recent decades. They are simple to perform and preserve the sphincters, thus limiting the risk of postoperative incontinence. However, they have a low cure rate with frequent recurrences, requiring repeat procedures or other techniques [7] [9]-[22] [31].

Since its initial description by Han et al., the LIFT-Plug has been evaluated several times. This method has shown better healing results than either of the two techniques alone. Indeed, success rates after anal plug placement or LIFT vary from $20 \%$ to $86.7 \%$ [7] [9] [10] [11] [12] and $40 \%$ to $95 \%$ [13]-[18] respectively, depending on the study. High recurrence rates are high and range from $0 \%$ to $26.3 \%$ [11] [12] and $6.4 \%$ to $28 \%$ [19] [20] [21] [22] for anal plug and LIFT respectively. Moreover, these results seem to deteriorate over time [32]. The LIFT-Plug gives better results with cure rates of $94 \%-96.5 \%$ and minimal recurrence [17] [18] [24] [25]. However, Tan et al. found a success rate of $68.8 \%$ with an average delay of 3 weeks between surgery and diagnosis of failure [26]. In our study, the LIFT-Plug has a 100\% cure rate and no recurrence at 6 months follow-up. However, this follow-up time is much shorter than that of many au- 
thors [11] [14] [16] [18] [24], and when we know that the results fade with time [32]. Indeed, Eduardo and al found a median time to recurrence of 24.8 weeks after inter-sphincter ligation [16]. In addition, patients with specific fistulas, other anal lesions, or defects that could impede the healing process were excluded. Two studies comparing LIFT with LIFT-Plug found a statistically significant higher success rate with the LIFT-Plug technique and a shorter healing time, despite a longer operative time [17] [18]. The average operating time in our series was 55.2 minutes, which is longer than the 17 to 28.5 minutes of other authors [17] [23] [24] [25]. The LIFT-Plug is a new technique in our therapeutic arsenal and therefore requires more learning. The average time to healing was 63.2 days. It was 4 weeks for Cianci et al. after LIFT [13]. It is much shorter after LIFT-Plug [17] [18] [23] [24] [25]. This high healing time in our study could be explained by the material used, which does not have the cell repopulation and revascularisation properties of conventional materials. In addition, it has an anti-adherent face which would delay its incorporation into the host tissue.

Preservation of continence remains a major goal in the treatment of anal fistula. While conventional techniques may result in unacceptable levels of incontinence in some cases [1] [2] [3] [4] [5], sphincter-sparing techniques, by preserving the sphincters, have minimal impact on continence. For example, fibrin sealant injection, anal plug and LIFT have very little impact on continence [12] [14] [20] [21] [33]. The LIFT-Plug, as well as the LIFT and anal plug, preserve the sphincters and thus the continence of the patients. Three of our patients presented with transient gas incontinence and none of the patients presented with continence problems at the end of the 6-month follow-up. Compared with LIFT and LIFT-Plug, these results are similar [14] [17] [20] [21] [23] [24] [26].

No major adverse events were noted. However, a significant proportion of our patients $(60.7 \%)$ presented with tingling that regressed spontaneously. No cases of intolerance or infection of the plug were recorded, apart from the delay in healing already mentioned. In contrast to our series, several authors have reported cases of spontaneous expulsion of the plug, often signifying failure of the procedure [11] [24] [33]. However, these promising results need to be followed up for a long time in order to consolidate the effectiveness of our procedure and to confirm the safety of our anal plug.

\section{Conclusion}

The LIFT-Plug is a simple, and effective technique for the treatment of high anal fistula without major impairment of continence despite delayed healing. The adapted two-sided prosthesis is a good alternative to the conventional anal plug. It is very well tolerated but a significant amount of time is needed to validate these results.

\section{Conflicts of Interest}

The authors declare no conflicts of interest regarding the publication of this paper. 


\section{References}

[1] Hämätäinen, K.P.J. and Sainio, A.P. (1997) Cutting Seton for Anal Fistulas: High Risk of Minor Control Defects. Diseases of the Colon \& Rectum, 40, 1443-1447. https://doi.org/10.1007/BF02070710

[2] Zbar, A.P., Ramesh, J., Beer-Gabel, M., Salazar, R. and Pescatori, M. (2003) Conventional Cutting vs. Internal Anal Sphincter Preserving Seton for High TransSphincteric Fistula: A Prospective Randomized Manometric and Clinical Trial. Techniques in Coloproctology, 7, 89-94. https://doi.org/10.1007/s10151-003-0016-6

[3] Vial, M., Parés, D., Pera, M. and Grande, L. (2010) Faecal Incontinence after Seton Treatment for Anal Fistulae with and without Surgical Division of Internal Anal Sphincter: A Systematic Review. Colorectal Disease, 12, 172-178. https://doi.org/10.1111/j.1463-1318.2009.01810.x

[4] Williams, J.G., MacLeod, C.A., Rothenberger, D.A. and Goldberg, S.M. (1991) Seton Treatment of High Anal Fistulae. British Journal of Surgery, 78, 1159-1161. https://doi.org/10.1002/bjs.1800781004

[5] Ritchie, R.D., Sackier, J.M. and Hodde, J.P. (2009) Incontinence Rates after Cutting Seton Treatment for Anal Fistula. Colorectal Disease, 11, 564-571. https://doi.org/10.1111/j.1463-1318.2008.01713.x

[6] Pigot, F. (2002) Satisfaction des malades après traitement chirurgical d'une fistule anale. Courrier Coloproctol, 2, 43-44.

[7] Johnson, E.K., Gaw, J.U. and Armstrong, D.N. (2006) Efficacy of Anal Fistula Plug vs Fibrin Glue in Closure of Anorectal Fistulas. Diseases of the Colon \& Rectum, 49, 371-376. https://doi.org/10.1007/s10350-005-0288-1

[8] Rojanasakul, A., Pattanaarun, J., Sahakitrungruang, C. and Tantiphlachiva, J.K. (2007) Total Anal Sphincter Saving Technique for Fistula-in-Ano, the Ligation of Intersphincteric Fistula Tract. Journal of the Medical Association of Thailand, 90, 581-586.

[9] Ortiz, H., Marzo, J., Ciga, M.A., Oteiza, F., Armendáriz, P. and de Miguel, M. (2009) Randomized Clinical Trial of Anal Fistula Plug versus Endorectal Advancement Flap for the Treatment of High Cryptoglandular Fistula in Ano. British Journal of Surgery, 96, 608-612. https://doi.org/10.1002/bjs.6613

[10] Fält, U.A., Zawadzki, A., Starck, M., Bohe, M. and Johnson, L.B. (2021) Long-Term Outcome of the Surgisis $^{\circledast}$ (Biodesign ${ }^{\circledR}$ ) Anal Fistula Plug for Complex Cryptoglandular and Crohn's Fistulas. Colorectal Disease, 23, 178-185.

https://doi.org/10.1111/codi.15429

[11] Tao, Y., Zheng, Y., Gang Han, J., Wang, Z.J., Cui, J.J., Zhao, B.C., et al. (2020) LongTerm Clinical Results of Use of an Anal Fistula Plug for Treatment of Low TransSphincteric Anal Fistulas. Medical Science Monitor, 26, e928181. https://doi.org/10.12659/MSM.928181

[12] Hansen, M.S., Kjær, M.L. and Andersen, J. (2019) Efficacy of Plug Treatment for Complex Anorectal Fistulae: Long-Term Danish Results. Annals of Coloproctology, 35, 123-128. https://doi.org/10.3393/ac.2018.07.14

[13] Cianci, P., Tartaglia, N., Fersini, A., Giambavicchio, L.L., Neri, V. and Ambrosi, A. (2019) The Ligation of Intersphincteric Fistula Tract Technique: A Preliminary Experience. Annals of Coloproctology, 35, 238-241.

https://doi.org/10.3393/ac.2018.08.16.1

[14] Wen, K., Gu, Y.F., Sun, X.L., Wang, X.P., Yan, S. and He, Z.Q. (2018) Long-Term Outcomes of Ligation of Intersphincteric Fistula Tract for Complex Fistula-in-Ano: Modified Operative Procedure Experience. Arquivos Brasileiros de Cirurgia Diges- 
tiva, 31, e1404. https://doi.org/10.1590/0102-672020180001e1404

[15] Xu, Y. and Tang, W. (2017) Ligation of Intersphincteric Fistula Tract Is Suitable for Recurrent Anal Fistulas from Follow-Up of 16 Months. BioMed Research International, 2017, Article ID: 3152424. https://doi.org/10.1155/2017/3152424

[16] Araújo, S.E.A., Marcante, M.T., Mendes, C.R.S., Bertoncini, A.B., Seid, V.E. and Horcel, LA. (2017) Interesfincterial Ligation of Fistula Tract (Lift) for Patients with Anal Fistulas: A Brazilian Bi-Institutional Experience. Arquivos Brasileiros de Cirurgia Digestiva, 30, 235-238. https://doi.org/10.1590/0102-6720201700040002

[17] Han, J.G., Wang, Z.J., Zheng, Y., Chen, C.W., Wang, X.Q. and Che, X.M. (2016) Ligation of Intersphincteric Fistula Tract vs Ligation of the Intersphincteric Fistula Tract plus a Bioprosthetic Anal Fistula Plug Procedure in Patients with Transsphincteric Anal Fistula: Early Results of a Multicenter Prospective Randomized Trial. Annals of Surgery, 264, 917-922. https://doi.org/10.1097/SLA.0000000000001562

[18] Zheng, Y., Wang, Z., Yang, X., Cui, J., Chen, C. and Zhang, X. (2015) A Multicenter Randomized Controlled Clinical Trial of Ligation of the Intersphincteric Fistula Tract plus Bioprosthetic Anal Fistula Plug in the Treatment of Chronic Anal Fistula. Chinese Medical Journal, 95, 3454-3457.

[19] Tan, K.K., Tan, I.J., Lim, F.S., Koh, D.C. and Tsang, C.B. (2011) The Anatomy of Failures Following the Ligation of Intersphincteric Tract Technique for Anal Fistula: A Review of 93 Patients over 4 Years. Diseases of the Colon \& Rectum, 54, 13681372. https://doi.org/10.1097/DCR.0b013e31822bb55e

[20] Khadia, M., Muduli, I.C., Das, S.K., Mallick, S.N., Bag, L. and Pati, M.R. (2016) Management of Fistula-in-Ano with Special Reference to Ligation of Intersphincteric Fistula Tract. Nigerian Journal of Surgery, 22, 1-4. https://doi.org/10.4103/1117-6806.169818

[21] Sirikurnpiboon, S., Awapittaya, B. and Jivapaisarnpong, P. (2013) Ligation of Intersphincteric Fistula Tract and Its Modification: Results from Treatment of Complex Fistula. World Journal of Gastrointestinal Surgery, 5, 123-128. https://doi.org/10.4240/wjgs.v5.i4.123

[22] Ooi, K., Skinner, I., Croxford, M., Faragher, I. and McLaughlin, S. (2012) Managing Fistula-in-Ano with Ligation of the Intersphincteric Fistula Tract Procedure: The Western Hospital Experience. Colorectal Disease, 14, 599-603. https://doi.org/10.1111/j.1463-1318.2011.02723.x

[23] Han, J.G., Yi, B.Q., Wang, Z.J., Zheng, Y., Cui, J.J., Yu, X.Q., et al. (2013) Ligation of the Intersphincteric Fistula Tract plus a Bioprosthetic Anal Fistula Plug (LIFTPlug): A New Technique for Fistula-in-Ano. Colorectal Disease, 15, 582-586. https://doi.org/10.1111/codi.12062

[24] Zhao, B., Wang, Z., Han, J., Zheng, Y., Cui, J. and Yu, S. (2019) Long-Term Outcomes of Ligation of the Inter-Sphincteric Fistula Tract plus Bioprosthetic Anal Fistula Plug (LIFT-Plug) in the Treatment of Trans-Sphincteric Perianal Fistula. Medical Science Monitor, 25, 1350-1354. https://doi.org/10.12659/MSM.914925

[25] Cui, J.J., Wang, Z.J., Zheng, Y., Han, J.G. and Yang, X.Q. (2012) Ligation of the Intersphincteric Fistula Tract plus Bioprosthetic Anal Fistula Plug (LIFT-Plug) in the Treatment of Transsphincteric Perianal Fistula. Chinese Journal of Gastrointestinal Surgery, 15, 1232-1235.

[26] Tan, K.K. and Lee, P.J. (2014) Early Experience of Reinforcing the Ligation of the Intersphincteric Fistula Tract Procedure with a Bioprosthetic Graft (BioLIFT) for Anal Fistula. ANZ Journal of Surgery, 84, 280-283.

https://doi.org/10.1111/ans.12242 
[27] Savom, E.P., Bwelle Motto, G.R., Bang, G.A., Ekani Boukar, M.Y., Guifo, M.L. and Essomba, A. (2016) Cutting Seton Fistulotomy for the Management of High Anal Fistula: Prospective Evaluation of Clinical Results in Yaoundé. Health Sciences and Disease, 17, 14-18.

[28] Jorge, J.M. and Wexner, S.D. (1993) Etiology and Management of Fecal Incontinence. Diseases of the Colon \& Rectum, 36, 77-97.

https://doi.org/10.1007/BF02050307

[29] Han, J.G., Xu, H.M., Song, W.L., Jin, M.L., Gao, J.S., Wang, Z.J., et al. (2009) Histologic Analysis of Acellular Dermal Matrix in the Treatment of Anal Fistula in an Animal Model. Journal of the American College of Surgeons, 208, 1099-1106. https://doi.org/10.1016/j.jamcollsurg.2009.02.052

[30] Beniker, D., McQuillan, D., Livesey, S., Urban, R.M., Turner, T.M., Blum, B., et al. (2003) The Use of Acellular Dermal Matrix as a Scaffold for Periosteum Replacement. Orthopedics, 26, s591-s596. https://doi.org/10.3928/0147-7447-20030502-13

[31] Kontovounisios, C., Tekkis, P., Tan, E., Rasheed, S., Darzi, A. and Wexner, S.D. (2016) Adoption and Success Rates of Perineal Procedures for Fistula-in-Ano: A Systematic Review. Colorectal Disease, 18, 441-458.

https://doi.org/10.1111/codi.13330

[32] Adamina, M., Ross, T., Guenin, M.O., Warschkow, R., Rodger, C., Cohen, Z., et al. (2014) Anal Fistula Plug: A Prospective Evaluation of Success, Continence and Quality of Life in the Treatment of Complex Fistulae. Colorectal Disease, 16, 547-554. https://doi.org/10.1111/codi.12594

[33] Saba, R.B., Tizmaghz, A., Ajeka, S. and Karami, M. (2016) Treating anal Fistula with the Anal Fistula Plug: Case Series Report of 12 Patients. Electronic Physician, 8, 2304 2307. https://doi.org/10.19082/2303 